\title{
Design and Implementation of a Fiber to the Home FTTH Access Network based on GPON
}

\author{
Mahmoud M. Al-Quzwini \\ College of Engineering, Al-Nahrain University, Baghdad, Iraq
}

\begin{abstract}
This paper presents a step by step design and field implementation of a protected GPON FTTH access network serving 1000 users. The basic components of the network are presented and the contribution of each component to the architecture of the FTTH network is addressed. The design incorporates Class B protection, to provide redundancy in the feeder and GPON port, the practical implementation of a protected FTTH network is highly emphasized.
\end{abstract}

\section{Indexing terms/Keywords}

GPON, FTTH, broadband, Fiber Optics communications

\section{INTRODUCTION}

Growing demand for high speed internet is the primary driver for the new access technologies which enable experiencing true broadband. It leads telecommunication operators to seriously consider the high volume roll-out of optical-fiber based access networks. They have to renew their access networks that are clearly becoming the bottleneck in terms of bandwidth. Therefore most telecommunication providers are currently withdrawing their legacy copper network, giving way to optical fiber networks. To allow faster connections, the optical fiber gets closer and closer to the subscriber. Fiber To The Home FTTH appears the most suitable choice for a long term objective: if the clients are wholly served by optical fibers, it will be easier to increase the bandwidth in the future [2]. FTTH is future proof solution for providing broadband services such as Video on demand, Online Gaming, HD TV and VoIP.

Passive optical network (PON) based FTTH access network is a point-to-multipoint, fiber to the premises network architecture in which unpowered optical splitters are used to enable a single optical fiber to serve multiple premises, typically 32-128 [9]. Fiber to the Home networks exploit the low attenuation $(0.2-0.6 \mathrm{~dB} / \mathrm{km})$ and high bandwidth $(>30,000 \mathrm{GHz})$ of single mode optical fibers [12] to provide many times more bandwidth than currently available with existing broadband technologies. In addition, these networks have the ability to provide all communication services viz. voice, data and video from one network platform [33].

Several Time Division Multiplexing TDM PON technologies are standardized for FTTH deployments, Table 1 summarizes these standards with their important parameters [3], [15], [21], [33]. The main disadvantage of TDM PON is that it not possible for different operators to physically share the same fiber. A multi-fiber deployment is necessary to physically share the access network [15].
Wavelength Division Multiplexing Passive Optical Networks WDM PONs are the next generation in the development of access networks. Two flavors of WDM-PON are being studied by Study Group 15 (SG15) of the International Telecommunication Union-Telecommunication Standardization Sector (ITU-T) [15]. The first one is time and wavelength division multiplexing PON (TWDM PON) which transmits 4-16 wavelengths on the same fiber to support higher number of users per fiber at higher transmission rates or more importantly to allow more than one operator sharing the same fiber, i.e. Operators can work with different wavelengths [15]. The second one is arrayed waveguide grating (AWG)-based WDM-PON which aimed to provide each user with a dedicated wavelength, similar to $\mathrm{P} 2 \mathrm{P}$, supporting $1.25 \mathrm{Gbps}$ downstream and upstream transmission capacity [15], [32].

GPON FTTH architecture offers converged data and voice services at up to $2.5 \mathrm{Gbps}$. GPON enables transport of multiple services in their native format, specifically TDM and data. In order to enable easy transition from BPON to GPON, many functions of BPON are reused for GPON. The GPON standards are known as ITU-T Recommendations G.984.1 through G.984.5. The GPON's uses Generic Framing Procedure (GFP) protocol to provide support for both voice and data oriented services. A big advantage of GPON over other schemes is that interfaces to all the main services are provided and in GFP enabled networks packets belonging to different protocols can be transmitted in their native formats [29], [30]. The voice component can be represented as VOIP service (voice over IP, packet-switched protocol) and can be combined with data component in physical layer simulations. Finally, the video component can be represented as a RF video signal (traditional CATV) or as IPTV signal that also can be combined with data [4]

Different aspects of FTTH access networks have been discussed in literature, [1]-[10] address issues related to outside plant OSP, [11]-[14] consider the power efficiency of these networks, some issues related to the implementation cost associated with FTTH networks are discussed in [15][26], availability modeling of the networks are discussed in [27],[28], and [31]-[33] discuss issues and challenges related to next generation PONs. However, the results of these researches are suboptimal as they are not based on actual networks. Furthermore, despite of its importance and being supported by the well-known OLT brands, class B protection has not been considered in the analysis of any of these researches. This shortage in access network field experience motivates the publication of this paper. Moreover, this paper provides a hands-on experience on GPON FTTH access networks design, validation and implementation. 
Table 1. TDM PON standards

\begin{tabular}{|c|c|c|c|c|c|}
\hline Parameter & BPON & EPON & GPON & XGPON & 10G-EPON \\
\hline Standard & ITU-T G.983 & IEEE 802.3ah & ITU-T G.984 & ITU-T G.987 & IEEE 802.3av \\
\hline $\begin{array}{c}\text { Downstream data } \\
\text { Rate }\end{array}$ & $622 \mathrm{Mbps}$ & $1.25 \mathrm{Gbps}$ & $2.5 \mathrm{Gbps}$ & $10 \mathrm{Gbps}$ & $10 \mathrm{Gbps}$ \\
\hline Upstream data Rate & $155 \mathrm{Mbps}$ & $1.25 \mathrm{Gbps}$ & $1.25 \mathrm{Gbps}$ & $2.5 \mathrm{Gbps}$ & $\begin{array}{l}10 \mathrm{Gbps} / \text { Symmetric } \\
1 \mathrm{Gbps} / \text { Asymmetric }\end{array}$ \\
\hline
\end{tabular}

In addition to this section, the paper is organized as follows: section 2 introduces an explanation to the basic components of a GPON FTTH access network, section three presents the general architecture of these networks, section four discusses issues related to the traffic rates and flow mechanism, it also explains in details the idea of type B protection used in GPON FTTH access networks, section five charts the design steps and present the designed feeder network and part of the distribution network, the terminology used in addressing each part in the network is clarified in this section as well, section six discusses the procedure to validate the design of the network, section seven summarizes the implementation steps and finally section eight wraps up the paper with the important conclusions.

\section{COMPONENTS OF GPON FTTH ACCESS NETWORK}

A passive optical network (PON) is a point-to-multipoint, shared optical fiber to the premises network architecture in which unpowered optical splitters are used to enable a single optical fiber to serve multiple premises, typically 64-128. passive optical networks are typically passive, in the sense that they employ a simple passive optical splitter and combiner for data transport. A PON takes advantage of wavelength division multiplexing (WDM), using one wavelength for downstream traffic and another for upstream traffic on a single Non-zero dispersion-shifted fiber (ITU-T G.652).

\subsection{Optical Line Terminal OLT}

The Optical Line Terminal (OLT) is the main element of the network and it is usually placed in the Local Exchange and it's the engine that drives FTTH system [29]. The most important functions that OLT perform are traffic scheduling, buffer control and bandwidth allocation [28]. OLTs typically operate using redundant DC power (-48VDC) and have at least 1 Line card for incoming internet, 1 System Card for onboard configuration, and 1 to many GPON cards. Each GPON card consists of a number of GPON ports.

\subsection{Optical Splitters}

The optical splitter splits the power of the signal. that is each link (fiber) entering the splitter may be split into a given number of fibers leaving the splitter and there is usually three or more levels of fibers corresponding to two or more levels of splitters. This enables sharing of each fiber by many users. Due to power splitting the signal gets attenuated but its structure and properties remain the same. The passive optical splitter need to have the following characteristics [29]:

- broad operating wavelength range

- low insertion loss and uniformity in any conditions

- minimal dimensions
- $\quad$ high reliability

- $\quad$ support network survivability and protection policy

\subsection{Optical Network Terminal ONT}

Optical Network Terminals (ONTs) are deployed at customer's premises. ONTs are connected to the OLT by means of optical fiber and no active elements are present in the link.

In GPON the transceiver in the ONT is the physical connection between the customer premises and the central office OLT. WDM triplexer module separates the three wavelengths $1310 \mathrm{~nm}, 1490 \mathrm{~nm}$ and $1550 \mathrm{~nm}$ (for CATV service). ONT receives data at $1490 \mathrm{~nm}$ and sends burst traffic at $1310 \mathrm{~nm}$. Analogue video at $1550 \mathrm{~nm}$ is received. Media Access Controller (MAC) controls the upstream burst mode traffic in an orderly manner and ensures that no collision occur due to upstream data transmission from different homes [29]

They are fiber to copper media converters that offer RJ11, RJ45, and F-Series connectors to any device. These devices are available in many configurations and port densities up to 24 ports. ONTs are available for outdoor and indoor use, provide POE or no POE, 10/100/1000, AES encryption, and can include batteries for survivability in the event of a power outage.

GPON uses Dynamic Bandwidth Allocation that is it dynamically allocates the bandwidth depending on the number of packets available in the T-CONT. Once the OLT reads the number of packets waiting in T-CONT it assigns the bandwidth. If there are no packets waiting in the T-CONT, then OLT assigns the bandwidth to other T-CONT which have packets waiting in T-CONT. If an ONT has a long queue OLT can assign multiple T-CONTS to that ONT [32].

\section{GPON FTTH ACCESS NETWORK ARCHITECTURE}

GPON's have a tree topology in order to maximize their coverage with minimum network splits, thus reducing optical power [3]. An FTTH access network comprises five areas, namely a core network area, a central office area, a feeder area, a distribution area and a user area as shown Figure 1. In [10] the core network area is not considered as a part of the FTTH access network. The network architecture adopted by this paper is to use two level of splitting between the central office and the user premises achieving an overall splitting ratio of 1:64. Level one splitter is $2: 4$ where the digit 2 comes from type $\mathrm{B}$ protection to be explained in section 4 . The distance between the OLT and ONT may be more than $20 \mathrm{~km}$ depending on the total available optical power budget, which is a factor of the OLT laser port and the total loss budget [29]. 


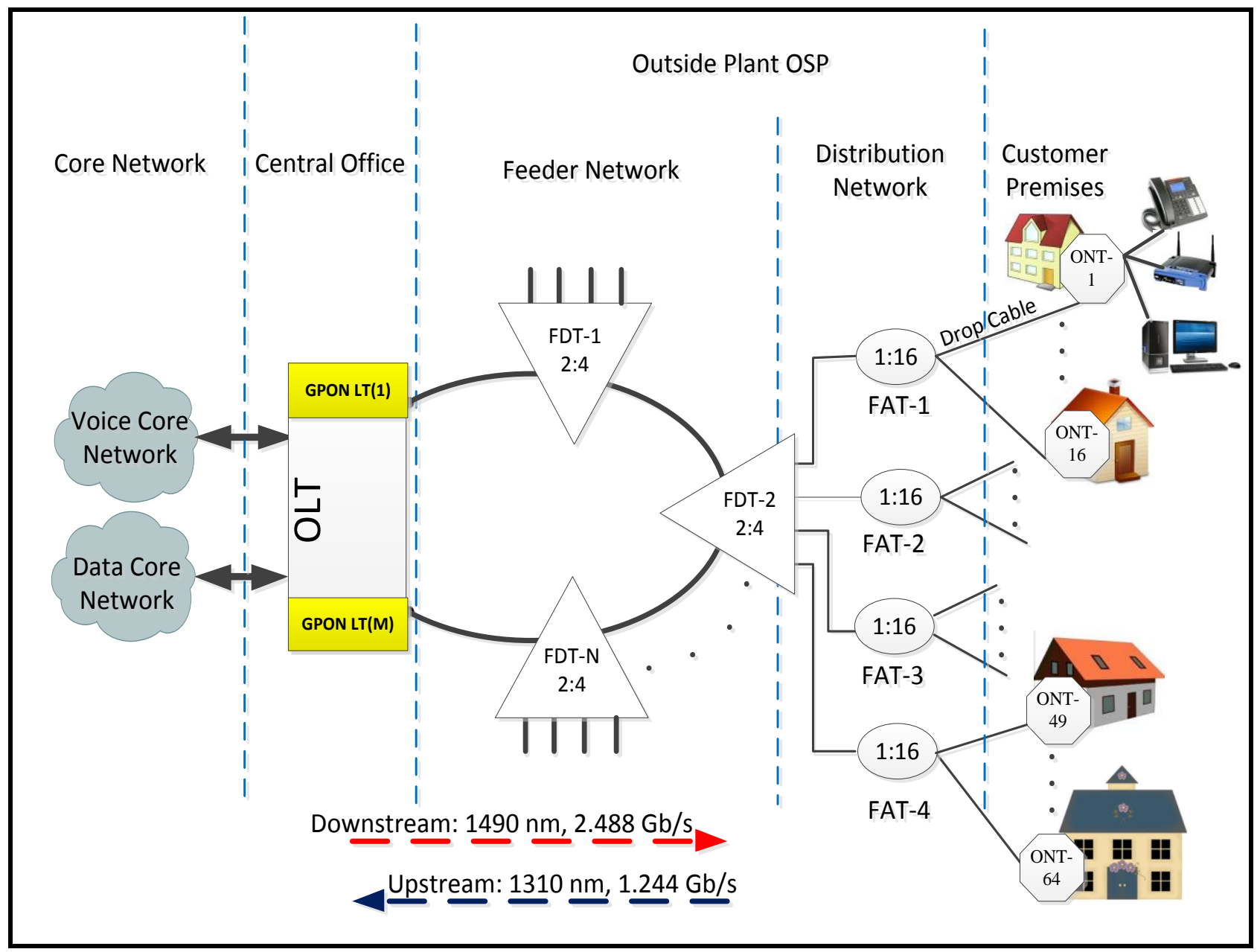

Fig. 1 GPON FTTH access network architecture

\subsection{FTTH Core Network}

The core network includes the internet service provider ISP equipments (typically BRAS and AAA server), PSTN (packet switched or the legacy circuit switched) and cable TV provider equipment.

\subsection{Central Office}

The main function of the central office is to host the OLT and ODF and provide the necessary powering. Sometimes it might even include some (or all) of the components of the core network.

\subsection{FTTH Feeder Network}

The feeder area extends from optical distribution frames (ODF) in the central office $\mathrm{CO}$ to the distribution points. These points, usually street cabinets, called Fiber Disruption Frames FDT where level-1 splitters usually reside. The feeder cable is usually connected as ring topology starting from a GPON port and terminated into another GPON port as shown in Fig. 1 to provide type B protection. Level-1 splitters with a spilt ratio of 2:4 have been employed by our design. This type of splitters enables the feeder to be connected to 2 GPON ports from one side (for type B protection) and feeds a total of 4 distribution cables from the other side. The fiber cable running between the CO and level-1 splitter is called Level-1 fiber [2]

\subsection{FTTH Distribution Network}

Distribution cable connects level-1 splitter (inside the FDT) with level-2 splitter. Level-2 splitter is usually hosted in a pole mounted box called Fiber Access Terminal FAT usually placed at the entrance of the neighborhood. In the design adopted by this paper level-2 splitter is $1: 16$, which means each FAT serves 16 homes. The fiber cable running between level-1 splitter and level-2 splitter is called level-2 fiber [2].

\subsection{User Area}

In the user area, drop cables, or level-3 fibers [2], are used to connect the level-2 splitter inside the FAT to the subscriber premises. Drop cables have less fiber count and length ranges up to 100 meters. Drop cables are designed with attributes such as flexibility, less weight, smaller diameter, ease of fiber access and termination. For ease of maintenance, usually an aerial drop cable is terminated at the entrance of the subscriber home with a Terminal Box TB, then an indoor drop cable connects the TB to an Access Terminal Box ATB reside inside the home. Finally a patch cord connects the ONT to the ATB.

It is most important that the optical fibers are distributed in such a way that efficient design, construction, maintenance and operation for FTTH is achieved. Therefore, in order to determine the network architecture, design, construction, maintenance, and operation approach for the optical access network, and to select optical components for FTTH, telecommunication companies should mainly consider the followings: [10] 
- Scalability

- Survivability

- Functionality

- Construction and maintenance costs

- Network upgradeability

- Operability and suitability over designed network lifetime.

\section{TRAFFIC FLOW IN GPON FTTH ACCESS NETWORKS}

The data is transmitted from OLT to ONT in downstream as a broadcast manner and as a Time Division Multiplexing (TDM) in upstream [32].The wavelength of the downstream data is $1490 \mathrm{~nm}$, voice and data services from core network transported over the optical network reaches the OLT and are distributed to the ONTs through the FTTH network by means of power splitting. Each Home receives the packets intended to it through its ONT. The upstream represents the data transmission from the ONT to OLT. The wavelength is 1310 $\mathrm{nm}$. If the signals from the different ONTs arrive at the splitter input at the same time and at the same wavelength $1310 \mathrm{~nm}$, it

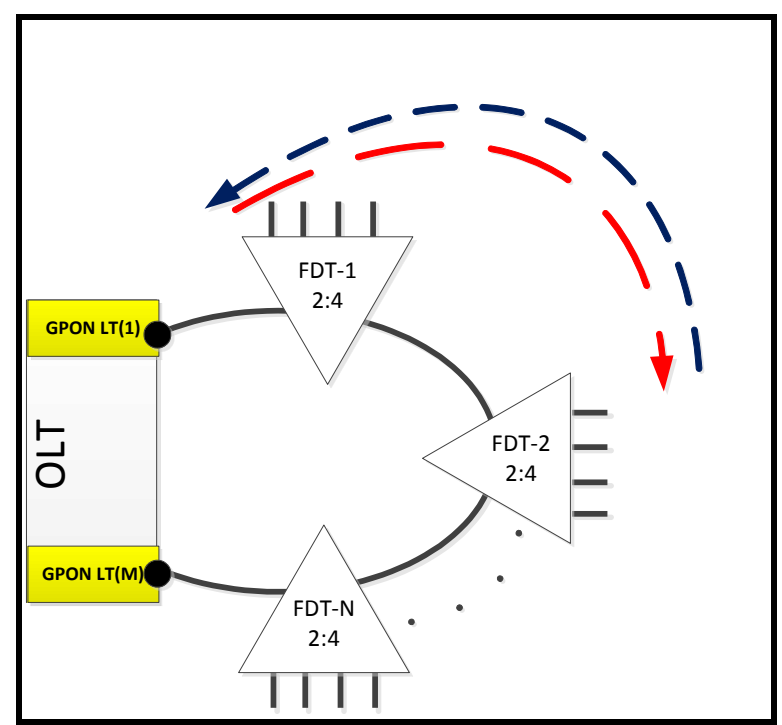

Fig. 2 Normal direction of traffic flow results in superposition of different ONT signals when it reaches OLT. Hence TDMA [1] is adopted to avoid the interference of signals from ONTs. In TDMA time slots will be provided to each user on demand for transmission of their packets. At the optical splitter packets arrive in order and they are combined and transmitted to OLT.

Type B protection [27], [34] is used in the design of the GPON FTTH access network presented in this paper. It provides redundancy against both feeder and GPON port failures. In this type of the protection, each fiber strand in the feeder cable is connected to two GPON ports in the OLT as shown in Figure 1. One of the ports is configured as active and the other as standby. Figure 2 shows the normal direction of traffic, once a failure in a fiber strand is happened, the OLT automatically activates the standby GPON port to broadcast a copy of the downstream traffic to feed the FDTs beyond the failure point from the other direction as shown in Figure 3. This standby GPON port will also receive the upstream traffic of the isolated feeder portion. Figure 4 depicts the situation when the active GPON port itself has a failure, in this case the OLT automatically divert the optical signal to the protection line through the standby GPON port.

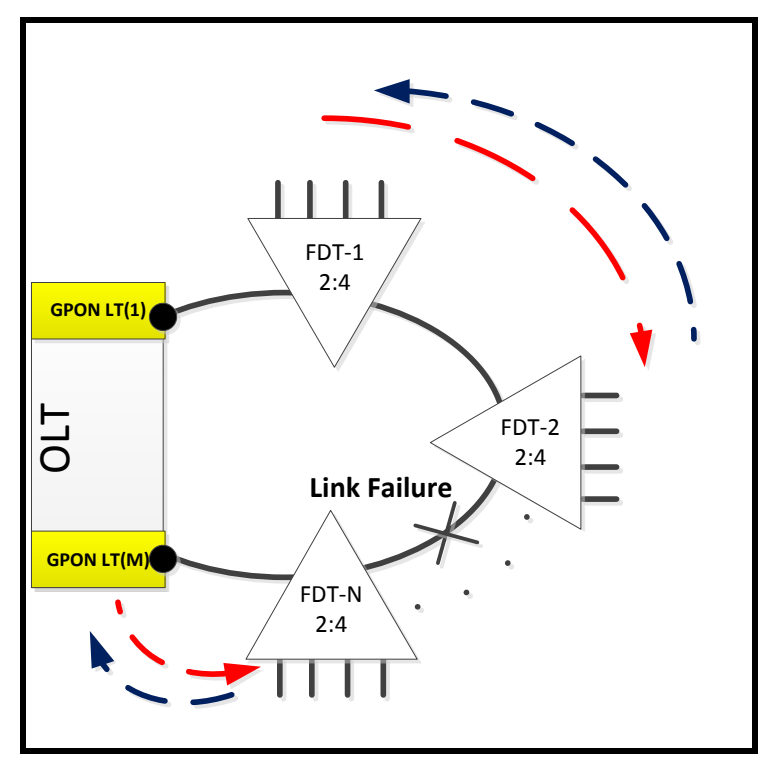

Fig. 3 Type B protection in GPON FTTH access network, the OLT send and receive traffic through the standby GPON ports to overcome link failure 


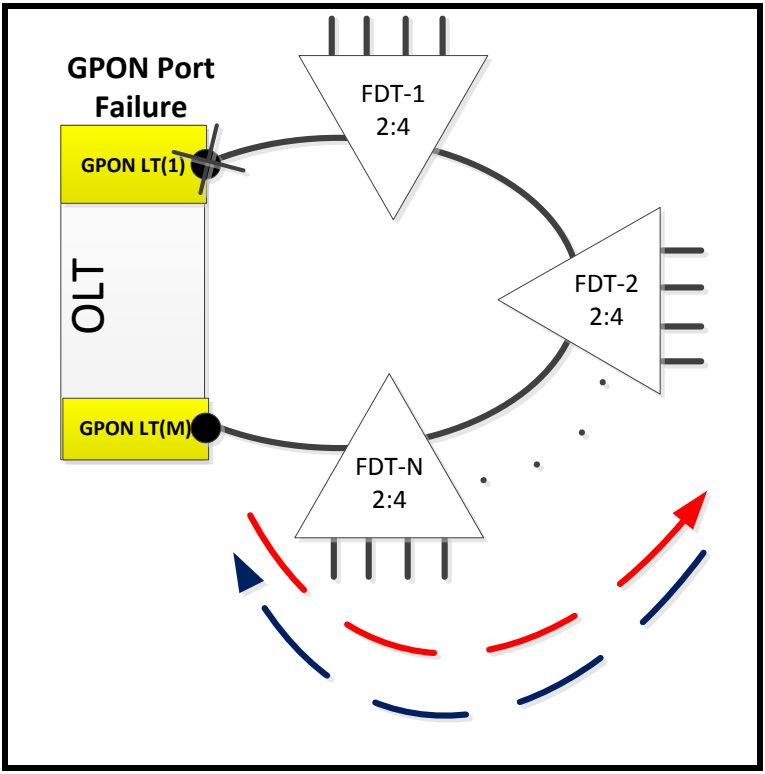

Fig. 4 Type B protection in GPON FTTH access network, the OLT sends and receives traffic through the standby GPON ports to overcome GPON-port failure

\section{DESIGN OF THE GPON FTTH ACCESS NETWORK}

The Design of an FTTH access network is challenging one; it needs to compromise different factors including size, cost, and scalability. There is no standard FTTH access network model as the viability of access networks strongly depends on the subscriber density (subscribers per $\mathrm{km} 2$ ) and on settlement structures, thus the modeling has to rely upon a concrete settlement structure, a given country, and the results derived depend on that country [18].

To design the Outside Plant OSP, Desk top planning does not work, each root is surveyed physically and then planned accordingly using knowledge and experience. International standards cannot be applied as each country has its own unique underground factors. Ground thermal line or freeze line should be considered to identify the point in the underground where the temperature of the surrounding soil remains constant (not freezing nor overheating) thus allowing for a constant temperature for the FO cable to lay in. Another important factor that should be addressed is to decide the depth and the type of the backfill material necessary to reduce the ground vibration effects.

Figure (5) summarizes the sequence of steps involved in the design of the FTTH access network in discussion. In reference to Figure 1, the design starts with the customer premises, moving backward until reaching the central office in a bottom-up approach. The network particularly considered in this paper is required to provide service (voice and data) to a total of 1000 users in 238 locations. According to the geographical separation of these locations and the number of users per individual location, 185 FATs are used to connect these locations to the network. Nearby locations are served by a common FAT while each of the diverse locations are served a by a dedicated FAT. Huawei MA5600T OLT located at the $\mathrm{CO}$ is used as the access platform. This OLT supports a 16 slots of 8-port GPON cards. Two level of splitting is used to provide a total splitting ratio of 64 . Level-1 splitters are 2-4 while level-2 splitters are 1:16. This means that each GPON port can serve a total of 64 users. A bottomtop approach is used to determine the required number of GPON ports. By simple math, we can see that 16 GPON ports with 64 split ratio are quite enough to serve 1000 users. This statement is true for FTTH networks where the locations are geographically located close to each other and the number of users distributed evenly among locations, which is not our case. Due to the constraints of our network, the number of required ports will be calculated depending on the number of FATs. According to the 64 splitting ratio, each GPON port can serve a total of 4 FATs as each FAT contain 1:16 splitter, then 48 GPON ports are required to serve the 185 FATs. Another bunch of redundant 48 GPON ports is used to provide type-B protection. The total number of OLT GPON cards used by the design will be 12 , with 6 cards in each direction. 6 FDTs are used to hold level-1 splitters with each FDT hold 8 splitters. As a result each FDT will be connected to one OLT card using 8 Fibers from one direction and to the backup card using 8 fibers from the other direction as shown in Figure 6. Two feeder rings are used, the first feeder consists 12 fibers among which 8 are connected to the 8 level1 splitters inside FDT-3. The second feeder forms the second ring connecting the other 5 FDTs. The extra 4 and 32 fibers, in the first and second feeders respectively, are reserved for future expansion or maintenance.

Figures 7 and 8 show the distribution network connected to FDT-3 and FDT-4 respectively, due to space limitation the other distribution networks will not be presented, however the design procedure discussed above is followed in the design of all distribution networks of the project. The legend presented in Figure 7 applies equally in Figure 8. Three distribution fiber cables connected to FDT-3, namely $3 / 1,3 / 2$, and $3 / 3$. The circles in the figures refer to splicing closures. The number inside the circle refers to the FDT/closure numbers, for example, $4 / 1$ refers to the first closure in FDT-4. The FATs are presented as ellipses in the design, the number inside each ellipse indicates the FAT address. The terminology adopted with FATs is to use 4 digit numbering. The first digit from the left refers to the FDT code, the second digit refers to the distribution cable sequence number and the last two digits refer to the sequence number of the fiber strand used to connect that FAT. This terminology applies equally to distribution networks connected all other FDTs. For example, in Figure 5, FAT number 4121 is an FAT in the first distribution cable of FDT-4, and connected to the 21th fiber strand of that distribution cable. This terminology makes the design, implementation management, reporting and future expansion easier. Two symbols are used for the FATs, the semicircle refers to FAT which only hold level-2 splitter, while the semicircle over a triangle refers to an FAT which holds level-2 splitter and provide splicing-closure function as well. The lines refer to FO cables paths. The length of each path, 


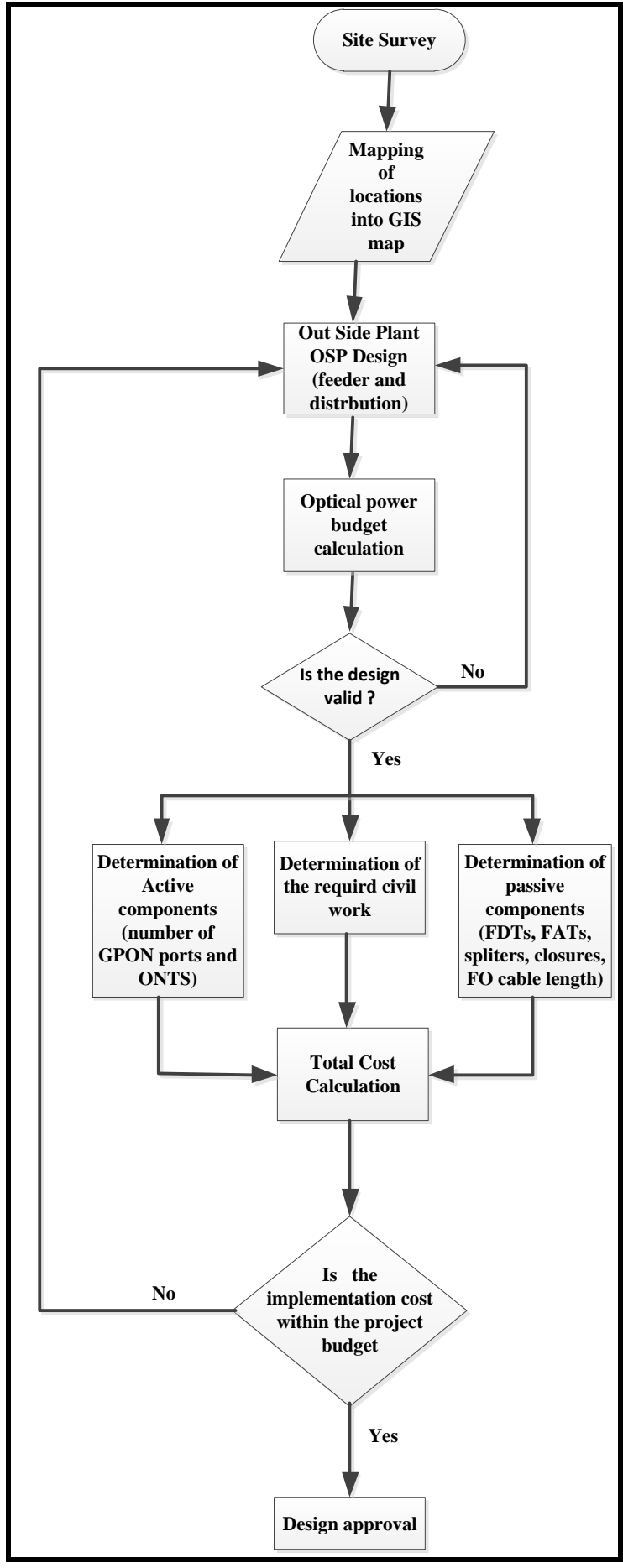

Fig. 5 GPON FTTH access network design steps

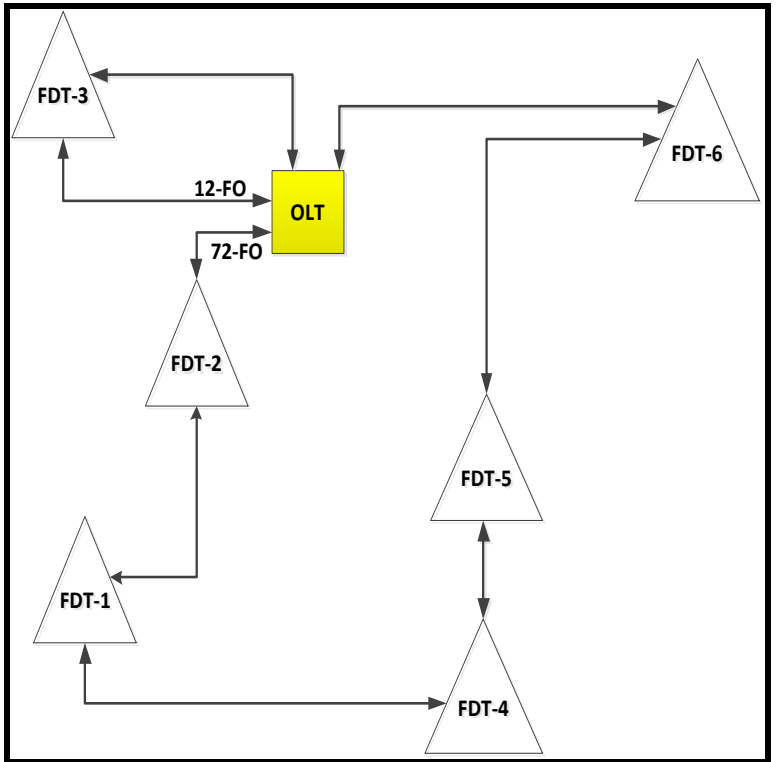

Fig. 6 The feeder part of the GPON FTTH access network

meters, is shown in the figures. The black lines represent trench paths, the red lines indicate areal paths, and the green lines refer to situations where electrical poles are used to carry distribution cables.

\section{DESIGN VALIDATION}

In order to assess the feasibility of the proposed design of the FTTH network and that each user in the network can receive adequate power, the total optical power loss between the GPON port of the OLT and that of the ONT should be considered. This loss can be summarized by the following equation:

loss $=l_{\text {cable }}+l_{\text {splitter }}+l_{\text {splice }}+l_{\text {conne ctor }}$

Table (2) presents the definition and value of each parameter in equation 1 .

The power received by the ONT at the receiver premises is:

Power received $=$ Power transmitted- loss

Where the power transmitted stands for the power emitted by the GPON interface in the OLT card which is $3 \mathrm{~dB}$ in this system. Table 2 shows the different values of losses, and the corresponding power received by individual ONTs. These losses are calculated according to the parameters presented in table (2). The locations considered in table (2) are chosen because they are the most remote in network; therefore represent the worst case power loss of the designed network. The calculations presented in this table show that the worst case received power is well above the $-26 \mathrm{~dB}$ ONT sensitivity. 
Table 2. Parameters contributing to the optical power loss in GPON FTTH access networks

\begin{tabular}{|c|l|c|}
\hline Parameter & \multicolumn{1}{|c|}{ Description } & Value \\
\hline$l_{\text {cable }}$ & $\begin{array}{l}\text { Account for the loss in optical signal power as it traverse the fiber cable, it is } \\
\text { measured in dB/km. OTDR is used to measure the exact value of this parameter. }\end{array}$ & $0.21 \mathrm{~dB} / \mathrm{km}$ \\
\hline$l_{\text {splitter }}$ & $\begin{array}{l}\text { Refers to splitter insertion loss, it varies according to the splitting ratio. The } \\
\text { values of used for this parameter are obtained from datasheets of the } \\
\text { corresponding splitter. }\end{array}$ & $\begin{array}{l}8 \mathrm{~dB} \text { for level-1 splitter. } \\
14 \mathrm{~dB} \text { for level-2 splitter }\end{array}$ \\
\hline$l_{\text {splice }}$ & $\begin{array}{l}\text { Represent the loss introduced due to splicing; it measured by the fusion splice } \\
\text { machine. The value shown represent the maximum loss obtained }\end{array}$ & $0.003 \mathrm{~dB}$ \\
\hline$l_{\text {connector }}$ & Manifests the loss introduced by connectors coupling. & $0.2 \mathrm{~dB}$ \\
\hline
\end{tabular}

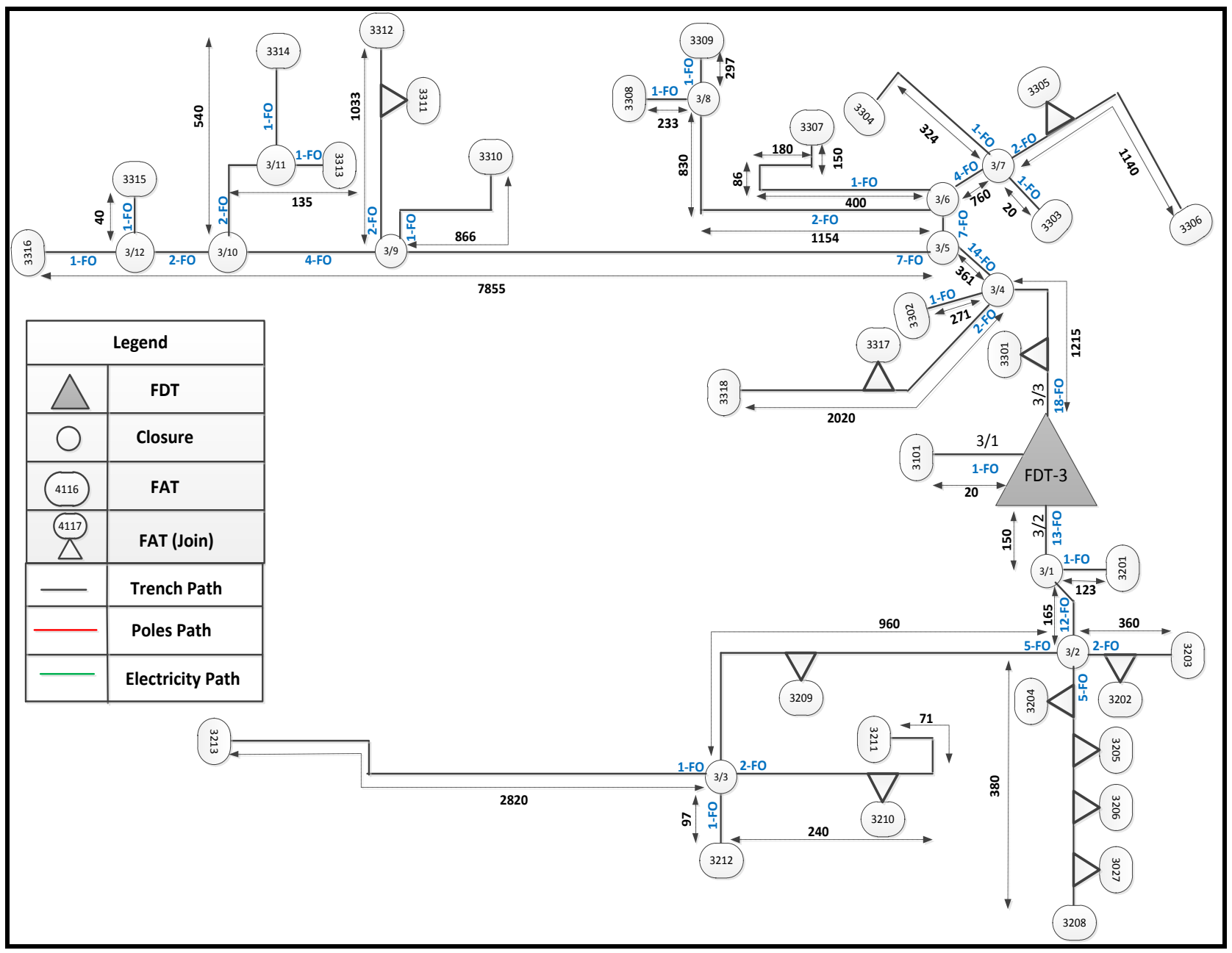

Fig. 7 The distribution network connected to FDT-3

\section{IMPLEMENTATION}

An engineering project should be implemented according to a pre-defined sequence of steps. This is especially crucial to projects which involve a mixer of engineering activities, where an error in a certain stage might lead to a propagation of error in the subsequent stages. FTTH projects are amongst such projects where they involve a mixer of civil and technical works. Project implementation planning saves time, efforts and cost. Therefore, a careful consideration is given to this issue. Figure 8 shows the major steps implemented in this project with their sequence. Special consideration is given to FO testing at the end of each step. Two methods are adopted in this project to determine the exact location of broken optical fiber in an installed optical fiber cable when the cable jacket is not visibly damaged. These are OTDR testing and laser source/power meter set. Optical Time Domain Reflectometer OTDR is used for attenuation monitoring and fault location in the feeder network while laser source/power meter is used for the other tests. Figures 10-19 show photos of the steps charted in figure 9 . 


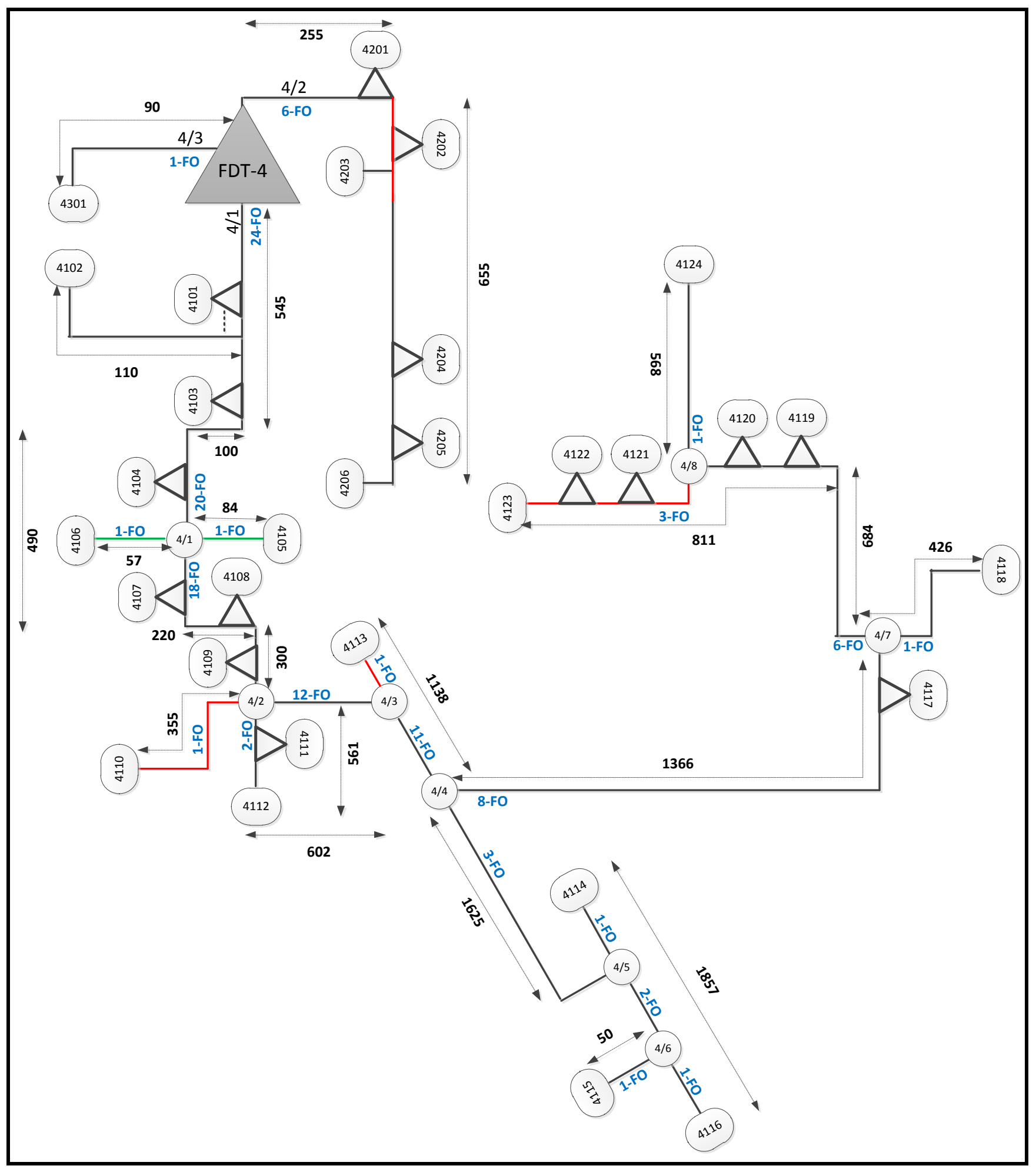

Fig. 8 The distribution network connected to FDT-4 
Table 3. Calculations of the optical power budget to validated the design

\begin{tabular}{|c|c|c|c|c|c|c|c|c|c|c|}
\hline FAT Code & $\begin{array}{c}\text { \# of } \\
\text { locations }\end{array}$ & $\begin{array}{c}\text { FDT-FAT } \\
\text { Distance } \\
\text { (meter) }\end{array}$ & $\begin{array}{c}\text { OLT-FDT } \\
\text { Distance } \\
\text { (meter) }\end{array}$ & $\begin{array}{c}\text { FAT-OLT } \\
\text { Distance } \\
\text { (meter) }\end{array}$ & $\begin{array}{l}\text { FO loss } \\
\text { (dB) }\end{array}$ & $\begin{array}{l}\text { connector } \\
\text { coupling } \\
\text { loss }(\mathrm{dB})\end{array}$ & $\begin{array}{l}\text { splicing } \\
\text { loss (db) }\end{array}$ & $\begin{array}{c}\text { \# of } \\
\text { closures }\end{array}$ & $\begin{array}{l}\text { closure- } \\
\text { splicing } \\
\text { loss (dB) }\end{array}$ & $\begin{array}{l}\text { Received } \\
\text { Power }(\mathrm{dB})\end{array}$ \\
\hline 3306 & 1 & 3476 & 1547 & 5023 & 1.055 & 1 & 0.12 & 4 & 0.012 & -21.187 \\
\hline 3316 & 1 & 9431 & 1547 & 10978 & 2.305 & 1 & 0.12 & 5 & 0.015 & -22.440 \\
\hline 3318 & 1 & 3235 & 1547 & 4782 & 1.004 & 1 & 0.12 & 1 & 0.003 & -21.127 \\
\hline 6407 & 1 & 1645 & 5057 & 6702 & 1.407 & 1 & 0.12 & 1 & 0.003 & -21.530 \\
\hline 6410 & 1 & 6002 & 5057 & 11059 & 2.322 & 1 & 0.12 & 2 & 0.006 & -22.448 \\
\hline 6413 & 1 & 9549 & 5057 & 14606 & 3.067 & 1 & 0.12 & 3 & 0.009 & -23.196 \\
\hline 3101 & 2 & 20 & 1547 & 1567 & 0.329 & 1 & 0.12 & 0 & 0 & -20.449 \\
\hline 3208 & 1 & 695 & 1547 & 2242 & 0.471 & 1 & 0.12 & 2 & 0.006 & -20.597 \\
\hline 3213 & 1 & 4095 & 1547 & 5642 & 1.185 & 1 & 0.12 & 3 & 0.009 & -21.314 \\
\hline 1101 & 2 & 2963 & 1616 & 4579 & 0.962 & 1 & 0.12 & 1 & 0.003 & -21.085 \\
\hline 1103 & 1 & 2880 & 1616 & 4496 & 0.944 & 1 & 0.12 & 3 & 0.009 & -21.073 \\
\hline 1105 & 1 & 4489 & 1616 & 6105 & 1.282 & 1 & 0.12 & 3 & 0.009 & -21.411 \\
\hline 1206 & 2 & 2165 & 1616 & 3781 & 0.794 & 1 & 0.12 & 1 & 0.003 & -20.917 \\
\hline 1217 & 1 & 4867 & 1616 & 6483 & 1.361 & 1 & 0.12 & 4 & 0.012 & -21.493 \\
\hline 1219 & 5 & 3432 & 1616 & 5048 & 1.060 & 1 & 0.12 & 2 & 0.006 & -21.186 \\
\hline 1226 & 1 & 5579 & 1616 & 7195 & 1.511 & 1 & 0.12 & 3 & 0.009 & -21.640 \\
\hline 6109 & 2 & 2215 & 5057 & 7272 & 1.527 & 1 & 0.12 & 4 & 0.012 & -21.659 \\
\hline 5102 & 1 & 150 & 2922 & 3072 & 0.645 & 1 & 0.12 & 0 & 0 & -20.765 \\
\hline 5208 & 2 & 470 & 2922 & 3392 & 0.712 & 1 & 0.12 & 0 & 0 & -20.832 \\
\hline 5318 & 2 & 2199 & 2922 & 5121 & 1.075 & 1 & 0.12 & 8 & 0.024 & -21.219 \\
\hline 4112 & 1 & 2216 & 2872 & 5088 & 1.068 & 1 & 0.12 & 2 & 0.006 & -21.194 \\
\hline 4116 & 1 & 6877 & 2872 & 9749 & 2.047 & 1 & 0.12 & 6 & 0.018 & -22.185 \\
\hline 4123 & 1 & 6156 & 2872 & 9028 & 1.896 & 1 & 0.12 & 6 & 0.018 & -22.034 \\
\hline 4206 & 1 & 910 & 2872 & 3782 & 0.794 & 1 & 0.12 & 0 & 0 & -20.914 \\
\hline
\end{tabular}

\section{CONCLUSIONS}

This paper presented a detailed design and implementation of a type B protected GPON based FTTH access network serving 1000 users, it adopted engineering approach to emphasize practical aspects and field experience. The design procedure followed a bottom top approach, in which the size of the network and its components is defined after analyzing the requirements, the number of locations, the geographical separation and the available infrastructure. OSP design should be based on the physical survey of each root, desk top design causes wasting of a lot of time and cost when some roots needs to be redesigned to fit with the physical environments or to avoid certain obstacle.
In order to assess the validity of the design, the optical power budgets is calculated for remote locations, and the results showed that the highest power loss was $-23.196 \mathrm{~dB}$ which is well below the upper limit. The implementation steps and testing procedures are discussed, these steps are summarized in an implementation chart. The adoption of the procedure presented in this paper has saved a lot of efforts, cost and it has speeded up project commission. 


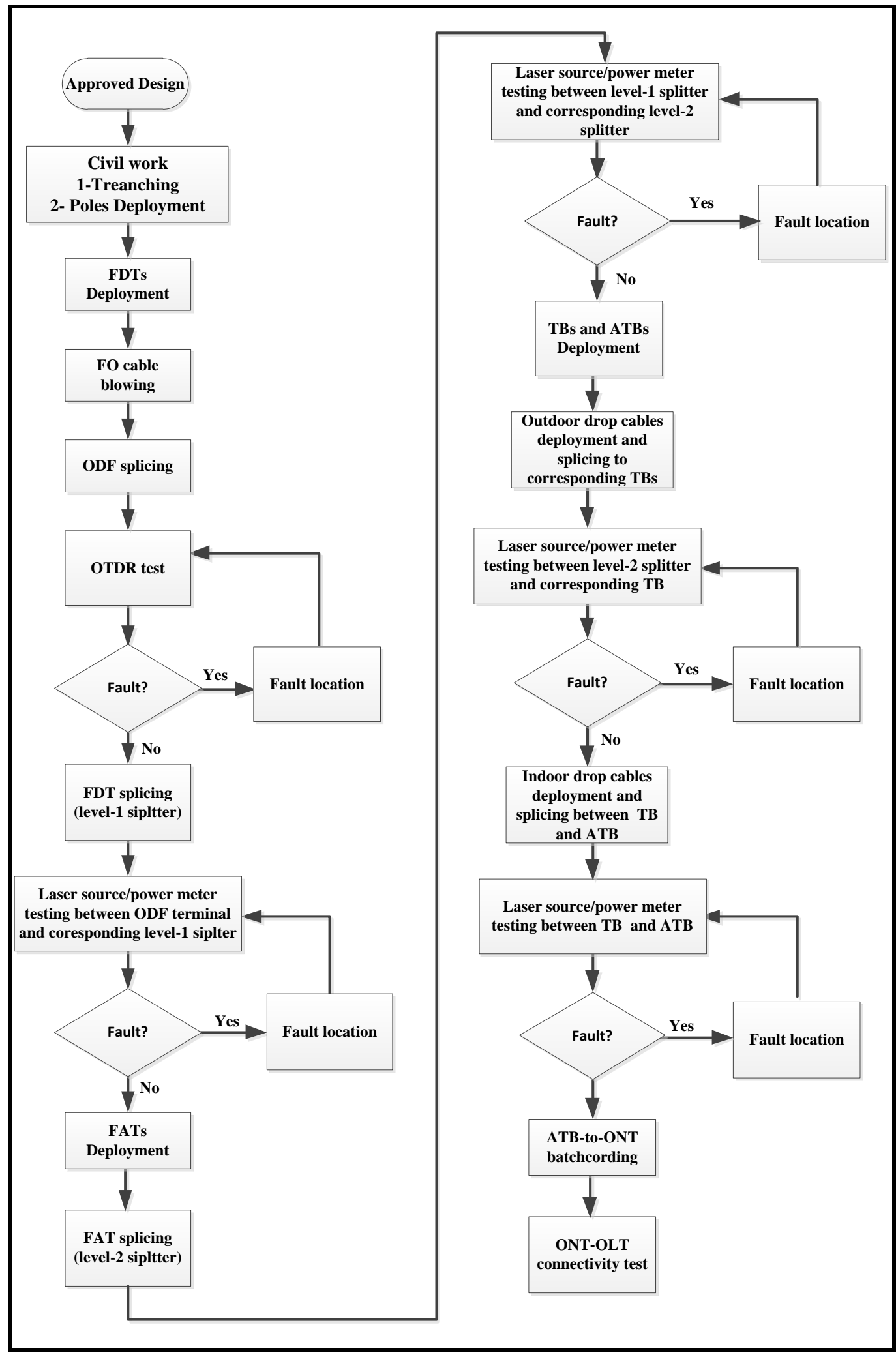

Fig. 9 Implementation steps of the GPON FTTH access network 


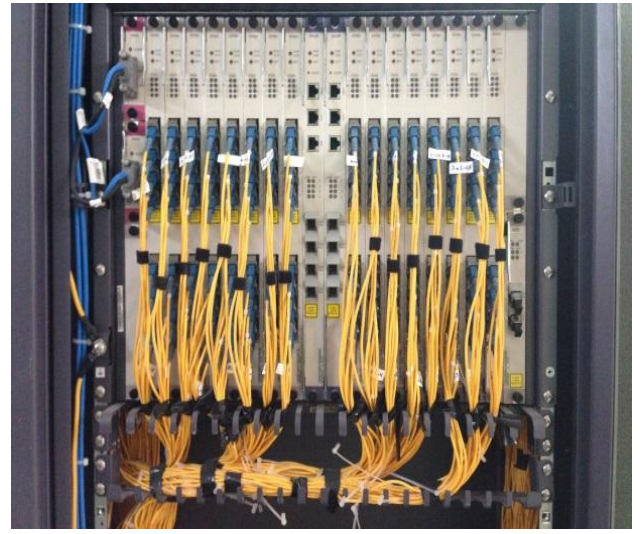

Fig. 10 the OLT

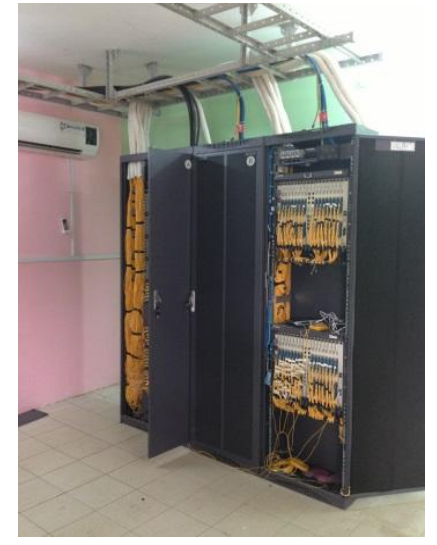

Fig. 11 The $\mathrm{CO}$ room showing the OLTs rack and the ODF

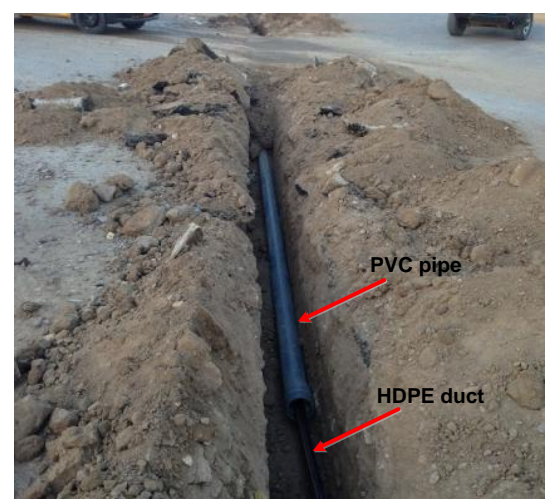

Fig. 12 Trenching

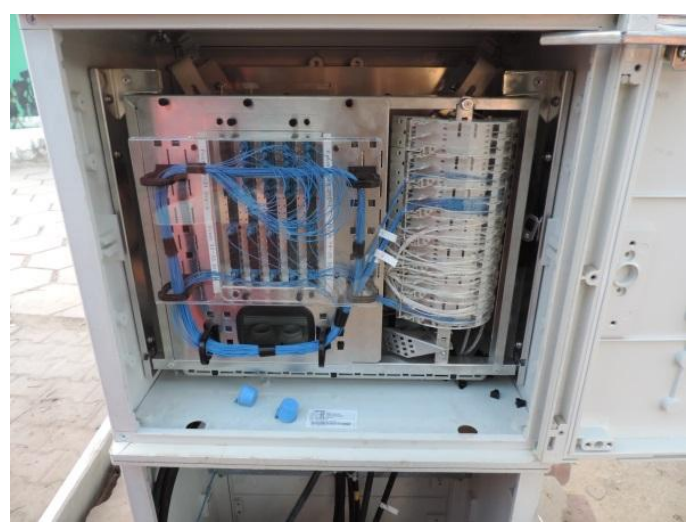

Fig. 13 Level-1 splitter inside the FDT

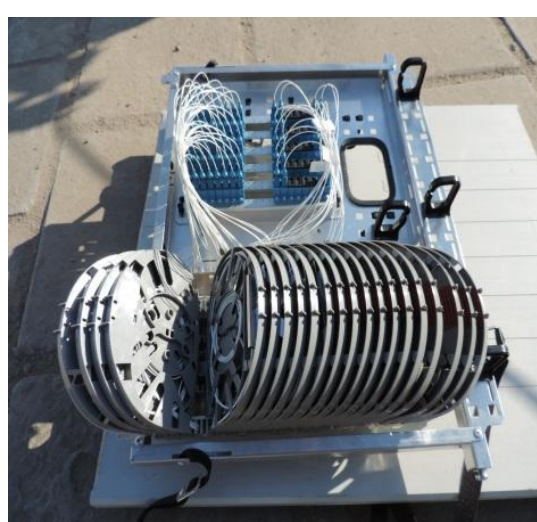

Fig. 14 FDT splicing brackets

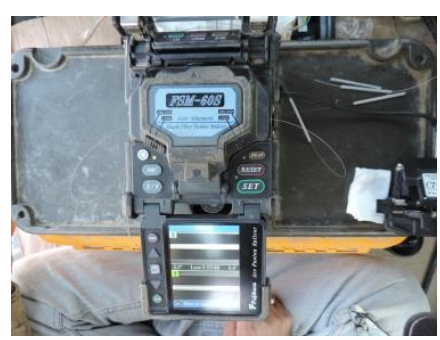

Fig. 15 Splicing process
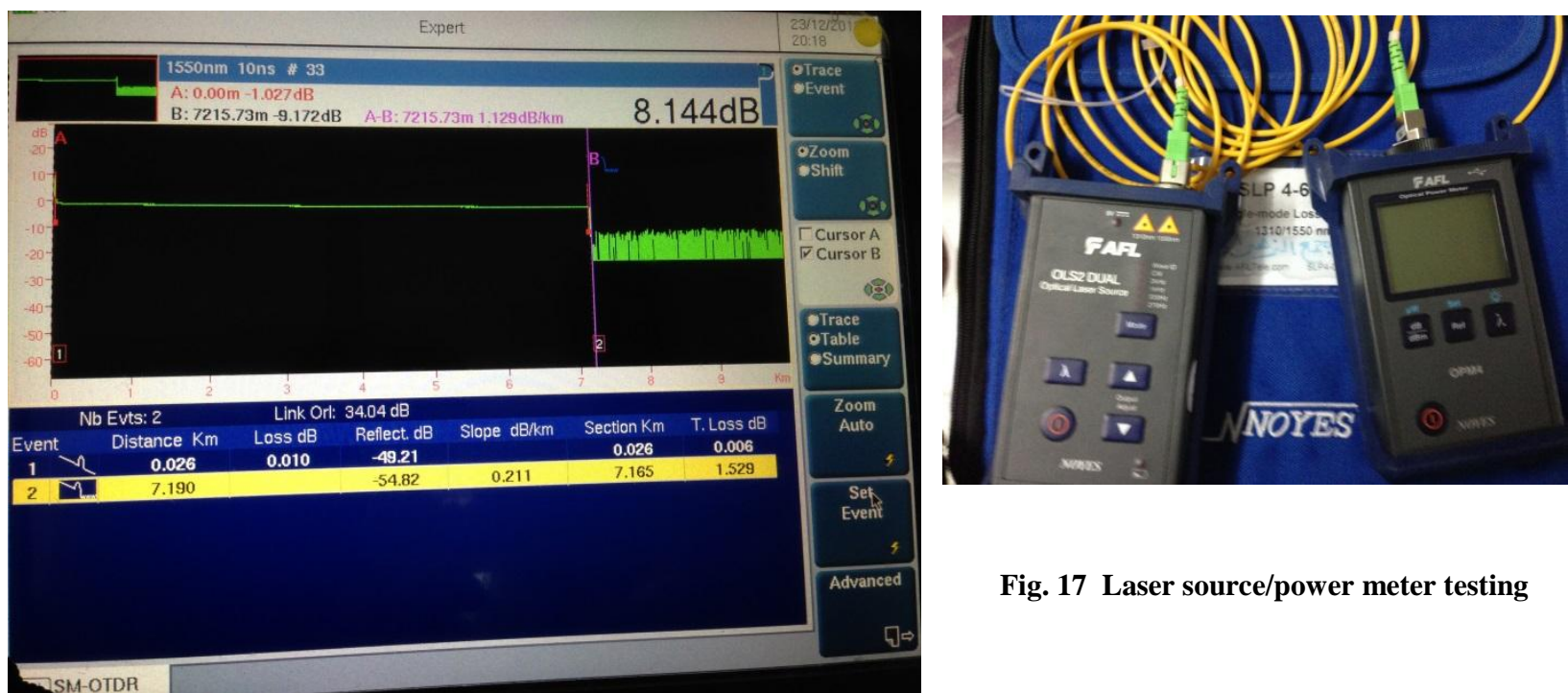

Fig. 17 Laser source/power meter testing

Fig. 16 OTDR testing screenshot 


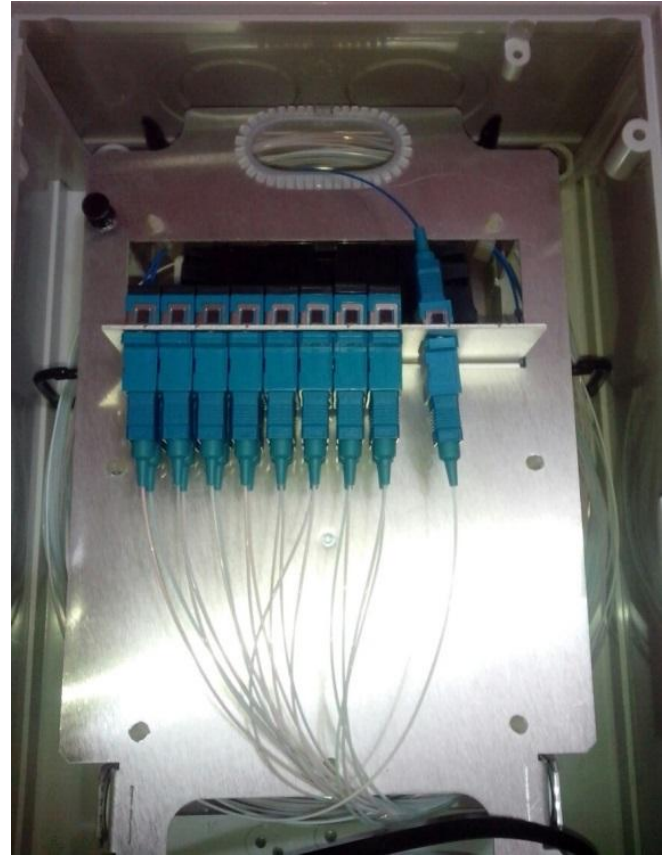

Fig. 18 level-2 splitter inside the FAT

\section{REFERENCES}

[1] Stephan Smith, "Business class services over a GPON network," in proc. IEEE Optical Fiber Communication Conference, 2006 and the 2006 National Fiber Optic Engineers Conference. OFC 2006.

[2] M. Chardy et al., "Optimizing splitter and fiber location in multilevel optical FTTH network," European Journal of Operational Research: Elsevier B.V, pp. 430-440, May 2012

[3] Deeksha Kocher et al., "Simulation of fiber to the home triple play services at $2 \mathrm{Gbit} / \mathrm{s}$ using GE-PON architecture for 56 ONUs," Optik: Elsevier B.V, pp. 5007-5010, 2013

[4] Deepak Malik et al., " Quality of service in two-stages epon for fiber-to- the-home," International Journal of Soft Computing and Engineering (IJSCE), vol. 2, No. 2, pp.387-390, May 2012.

[5] Mohd Syuhaimi Ab-Rahman et. al, "New optical splitter design for application in fibre-to-the home passive optical network using virtual lab platform," Journal of Computer Science: Science Publications, pp. 846-871, 2012.

[6] James O. "High speed data to the home - an update," in proc. 2011 IEEE International Conference on Consumer Electronics (ICCE), pp. 663-664, 2011.

[7] M. S. Rahman et al., "Ideal and non ideal condition analysis based on protection scheme in distributed fiber for immediate split Ftth-pon," Journal of Applied Science: Asian Network for Scientific Information, pp. 1026-1032, 2011

[8] Duo Peng and Peng Zhang, "Design of Optical Integrated Access Network Based on EPON," in proc. 2011 International Conference on Electronics and Optoelectronics (ICEOE 2011), pp. 65-68, 2011
[9] Rajneesh Kalera and R.S. Kalerb, "Simulation of Fiber to the Home at $10 \mathrm{Gbit} / \mathrm{s}$ using GE-PON architecture," Optik: Elsevier B.V, pp. 1362-1366, 2011.

[10] Bogyum KIM , Wonhyung LEE and Jinwoo HAN, "Outside Plant Architecture of Fiber-based Access Network," Digest of the 9th international conference on optical Internet (COIN 2010).

[11] Edoardo Bonetto, Marco Mellia, and Michela Meo, "Energy Profiling of ISP Points of Presence," in proc. IEEE ICC'12 Workshop on Green Communications and Networking, pp. 5973-5977, 2012.

[12] Salah Al-Chalabi, "Optically Powered Telephone System over Optical Fiber with High Service Availability and Low Risk of Investment in FTTH Infrastructure," IEEE Communications Magazine, August 2012.

[13] Christoph Lange and Andreas Gladisch, "On the Energy Consumption of FTTH Access Networks," IEEE,

[14] Andreas Gladisch , Christoph Lange and Ralph Leppla, "Power efficiency of optical versus electronic access networks," in proc. ECOC 2008, 21-25 September 2008, Brussels, Belgium, pp. 1-4.

[15] Juan Rendon Schneir and Yupeng Xiong, "Economic implications of a co-investment scheme for FTTH/PON architectures," Telecommunications Policy: Elsevier B.V, pp. 849-860. 2013.

[16] Stephan Jay, Karl-Heinz Neumann $\mathrm{n}$ and Thomas Plückebaum, "Comparing FTTH access networks based on P2P and PMP fibre topologies," Telecommunications Policy: Elsevier $\quad$ B.V, 2013 , http://dx.doi.org/10.1016/j.telpol.2013.04.010i.

[17] Zijad Havic and Branko Mikac, "Software tool for assessment of FTTH access networks," in proc. 12th International Conference on Telecommunications ConTEL 2013, pp. 47-52, June 2013. 
[18] Steffen Hoernig et al., "The impact of different fiber access network technologies on cost, competition and welfare," Telecommunications Policy: Elsevier B.V, 2012, pp. 96-112.

[19] Marco Araújo and A. Manuel de Oliveira Duarte, “A comparative study on cost-benefit analysis of fiber-tothe-home telecommunications systems in Europe," in proc. IEEE 2011 Baltic Congress on Future Internet and Communications, pp. 65-69.

[20] Marco Forzati et al., "The uncaptured value of FTTH networks,", in proc. IEEE 2011 13th International Conference on Transparent Optical Networks ICTON2011, pp. 1-4.

[21] Dirk Breuer et al., "Opportunities for Next-Generation Optical Access," IEEE Communications Magazine, February 2011

[22] Sotiria Chatzi and Ioannis Tomkos, “ Techno-economic study of high-splitting ratio PONs and comparison with conventional FTTH-PONs/FTTH-P2P/ FTTB and FTTC deployments," in proc. IEEE 2011 Optical Fiber Communication Conference and Exposition and the National Fiber Optic Engineers Conference, pp.1-3.

[23] Sofie Verbrugge et al., "Research Approach towards the Profitability of Future FTTH Business Models," in proc. 2011 Future Network \& Mobile Summit, pp. 1-10, 2011.

[24] Zijad Havic, "Economic Model Computing for FTTH Access Network," in proc. IEEE 5th International Conference on Pervasive Computing and Applications, pp. 218-222, 2010.

[25] Bruno Van Den Bossche et al., " Maximizing the return on investment for FTTX-rollout through the use of GIS street maps and geomarketing data," in proc. IEEE 2010 9th Conference of Telecommunication, Media and Internet, pp.1-6, 2010.
[26] Rong Zhao et al., "Dynamic Migration Planning towards FTTH," in proc. IEEE 2010 9th Conference of Telecommunication, Media and Internet, pp.1-6, 2010.

[27] Boyer Heard, "Availability and cost estimation of secured FTTH architectures," in proc. IEEE 2008 International Conference on Optical Network Design and Modeling, pp.1-6.

[28] Yinghui Qiu, "Availability estimation of FTTH architectures based on GPON," in proc. IEEE 2011 7th International Conference on Wireless Communications, Networking and Mobile Computing, pp. 1-4.

[29] Jani Saheb Shaik, "FTTH deployment options for telecom operators," www.sterlitetechnologies.com.

[30] Frank Effenberger et al., "An Introduction to PON Technologies," IEEE Communications Magazine, March 2007, pp. 517-525.

[31] Cláudio Rodrigues et al., "Evolution of FTTH Networks Based on Radio-Over-Fibre," in proc. IEEE 2011 13th International Conference on Transparent Optical Networks ICTON, pp. 1-4

[32] Satyanarayana Katlay and Abhinov Balagoni, "Technological and Cost based Analysis of Future-Proof Fiber Access Passive Networks: GPON and WDM PON," arXiv, pp. 1-4, 2013.

[33] Jagjit Singh Malhotra, Manoj Kumar and Ajay K. Sharma, "Low cost solution to high capacity $32 \times 32$ channel FTTH duplex link employing triple play services," Optik: Elsevier B.V, pp. 93-96, 2014.

[34] Josep Prat, Ed., Next-Generation Passive Optical Networks: Research Twords Unlimited Bandwidth Access, Springer, 2008. 